\title{
CAPSULE DEVELOPMENT, IN VITRO GERMINATION AND PLANTLET ACCLIMATIZATION IN PHRAGMIPEDIUM HUMBOLDTII, P. LONGIFOLIUM AND P. PEARCEI
}

\author{
Melania MuÑoz ${ }^{1} \&$ Víctor M. JiMÉNEZ ${ }^{2}$ \\ CIGRAS, Universidad de Costa Rica, 2060 San Pedro, Costa Rica \\ Jardín Botánico Lankester, Universidad de Costa Rica, P.O. Box 1031, 7050 Cartago, Costa Rica \\ ${ }^{1}$ melaniamunozg@yahoo.com; ${ }^{2}$ victor.jimenez@ucr.ac.cr
}

\begin{abstract}
Capsule development from pollination to full ripeness was evaluated in Phragmipedium longifolium, P. pearcei and P. humboldtii. Besides, seed viability, analyzed in each capsule by means of the tetrazolium chloride staining, was determined. Considering seed viability, germination rate was corrected and expressed as the rate of viable seeds that germinated in the presence and absence of light, on Knudson C and on half-strength Murashige and Skoog culture media. Capsule length remained constant during the evaluation period, while the diameter increased during the first 6-8 weeks and then stagnated. Capsule opening occurred 16 weeks after pollination in P. longifolium, after 9.8 weeks in $P$. pearcei and after 32 weeks in $P$. humboldtii. Seed viability averaged $44.7 \%$ in P. longifolium, $82.3 \%$ in P. pearcei and $34.3 \%$ in P. humboldtii. No significant effect of light conditions was evident in any of the species. However, a higher proportion of seeds of $P$. longifolium and $P$. pearcei germinated earlier on half-strength Murashige and Skoog medium than on Knudson C. Only 2.9\% of the viable seeds of $P$. humboldtii germinated, while approximately $40 \%$ germination occurred in the other two species. Initial growth of the embryos was better in the dark on Knudson $\mathrm{C}$ medium, compared to the other treatments studied. Further growth of the seedlings took place under light conditions. Developed plants formed roots and were successfully acclimatized in the greenhouse.
\end{abstract}

KEY WORDS: capsule development, in vitro seed germination, pollination, Phragmipedium, terrestrial orchids, tetrazolium chloride, tropical orchids

\section{Introduction}

Slipper orchids belonging to the genus Phragmipedium (Subfamily Cypripedioideae Lindl.) are distributed in Meso and South America (Cox et al. 1998, Dressler 2003). They are seriously threatened because of alteration and destruction of their habitat and over collection from their natural environment (Arditti 1992, Salazar 1996).

Use of in vitro protocols has been foreseen as a successful approach for ex-situ conservation and reintroduction of endangered orchids (Stenberg and Kane 1998, Decruse et al. 2003, Sarasan et al. 2006). Plants regenerated from seeds have a broader genetic background than those developed by clonal propagation methods. Therefore, the former meet the goals of a reintroduction program better, in the sense of warranting sufficient genetic resources in the reintroduced population to undergo adaptive evolutionary change (Guerrant and Kaye 2007).

This strategy has been successfully employed for the reintroduction of the orchid species Bletia urbana (Rubluo et al. 1989), Ipsea malabarica (Gangaprasad et al. 1999) and Spiranthes brevilabris (Steward et al. 2003). An additional advantage of mass-propagating orchids for conservation purposes is that increasing availability of plants from preferred species with adequate phytosanitary standards and at affordable prices would reduce illegal collection from the wild populations (Ramsay and Dixon 2003, Salazar and Mata 2003).

Propagation of Phragmipedium through seeds does not seem to be extremely difficult, because commercial formulations for asymbiotic germination in this genus are available. However, the composition 
of the culture media has remained elusive to the scientific community for commercial reasons. Most research on this and related genera is limited to studies on systematics and evolution (e.g., Cox et al. 1997, 1998). Investigations on phenology in this genus, describing characteristics of seed capsules and their development, are scarce (Arditti and Ghani 2000).

When proper conditions for germination are to be assessed, it is important to know the viability of the seeds under study. This allows distinguishing the proportion of seeds that do not germinate as a consequence of unfavorable germination conditions from those seeds that are not capable of germinating at all due to lack in viability. The most common method used to evaluate seed viability is the tetrazolium $\left(\mathrm{C}_{19} \mathrm{H}_{15} \mathrm{ClN}_{4}\right)$ stain. Dehydrogenases, which are active in living tissues, reduce the colorless tetrazolium chloride to a red compound, coloring viable seeds. The intensity of the tint could vary from pink to dark red (Singh 1981). This technique has been successfully used to test viability of orchid seeds (Lauzer et al. 1994, Vujanovic et al. 2000).

The aims of this study were to describe the development of P. humboldtii, P. longifolium, and $P$. pearcei capsules, to evaluate the seed viability and to establish a method for in vitro germination of mature seeds and for growing and acclimatizing plantlets of these three Phragmipedium species aiming at conservation.

\section{Materials and methods}

Pollination of flowers and capsule development. Manual pollination of flowers of Phragmipedium humboldtii, P. longifolium, and P. pearcei, growing at Lankester Botanical Garden, Universidad de Costa Rica, was conducted using pollen from a different plant. Capsule length, diameter and color were evaluated weekly, until full maturity. The time taken for each capsule to open was also recorded.

Seed viability. - The percentage of viable seeds was determined in each ripe capsule using the method of tetrazolium stain (Singh 1981). For that purpose, four subsamples of each of the two $P$. humboldtii, one $P$. longifolium, and four $P$. pearcei capsules were placed in tetrazolium chloride (1\%, $\mathrm{pH} 6-7)$, in a water bath $\left(30^{\circ} \mathrm{C}\right)$ and in dark conditions for $24 \mathrm{~h}$. Subsequently, they were transferred to Petri dishes and the percentage of viable (stained) seeds was determined with aid of a stereomicroscope (model 222279, Nikon). Seeds from the corresponding capsules were used in the germination studies.

In vitro germination. - Seeds from open capsules were sterilized in sodium hypochlorite $(\mathrm{NaOCl}$, $0.6 \% \mathrm{w} / \mathrm{v})$ and Tween $20(1 \mathrm{drop} / 100 \mathrm{ml})$ for 10 min. They were subsequently screened through sterile Albet ${ }^{\circledR}$ filter paper (quantitative quality), in the laminar hood. They were then rinsed three times with sterile distilled water, while adhered to the filter paper and, after decanting the water of the last rinse, distributed evenly, with a scalpel (blade No. 22) on $20 \mathrm{ml}$ of semisolid culture medium contained in 90 mm-Petri dishes.

Knudson C (Knudson 1946) and half-strength Murashige and Skoog (1962) mineral salts, both supplemented with $1 \mathrm{mg} \mathrm{l}^{-1}$ thiamine, nicotinic acid and pyridoxine, together with $20 \mathrm{~g} \mathrm{l}^{-1}$ sucrose, were compared for seed germination. $\mathrm{pH}$ was adjusted to 5.7 and media gelled with agar $(0.8 \%)$. Media were autoclaved at $1.05 \mathrm{~kg} \mathrm{~cm}^{-2}$ for $25 \mathrm{~min}$.

Additionally, two light regimes were evaluated during germination: dark conditions and photoperiod of 12 hours $\left(10.9 \mu \mathrm{mol} \mathrm{m} \mathrm{m}^{-2} \mathrm{~s}^{-1}\right.$, Sylvania Supersaver Cool White, $32 \mathrm{~W}, \mathrm{~F} 48 \% 12 / \mathrm{CW} / \mathrm{SS})$. Cultures were grown at $25 \pm 1^{\circ} \mathrm{C}$.

To determine the percentage of germination, three squares, of $1 \mathrm{~cm}^{2}$ each, were drawn in each Petri dish. Areas of the Petri dishes in which individual seeds could be clearly observed using a stereomicroscope were selected to draw the squares. Total number of seeds in each section was counted at the first day of culture. Afterwards, the number of germinating seeds (those in which rupture of the testa occurred by the enlarging embryo) was assessed weekly. Three Petri dishes were evaluated for every combination of culture medium, light condition and species. Considering seed viability, germination rate was corrected and expressed as the rate of viable seeds that germinated in each treatment. For example, if $50 \%$ of the seeds of a capsule with a $50 \%$ germination rate, according to the tetrazolium test, germinated on culture medium, it was considered that $100 \%$ of the 
viable seeds germinated. Besides, the percentage of dead protocorms (those that turned brown after germination) was calculated.

Protocorms growing in the dark were transferred to the same light conditions of the other treatment after six weeks of culture. Growing protocorms were subcultured every six weeks on the corresponding culture medium. Only actively growing and green protocorms were selected and individually subcultured. When the plantlets reached $1 \mathrm{~cm}$ in height, they were transferred into glass flasks (150 $\mathrm{ml}$ ), eight plants per flask. Later on, when they were 2-3 cm tall, only five plants were cultured per flask.

Plants were acclimatized approximately 15 months after culture beginning, when they were $4-5 \mathrm{~cm}$ tall and had 2-3 roots around $1 \mathrm{~cm}$ in length. For that purpose, all remnants of the gelled culture medium were carefully removed from the roots with running water. One plant was potted per plastic container (3 x $3 \times 4 \mathrm{~cm}$ ), carefully covering the roots completely with the potting mix (peat moss). Plants were placed under mist irrigation (4 $\mathrm{s}$ watering every $15 \mathrm{~min}$ during the daylight hours). After six months in the greenhouse, the average number of roots and the size of the longest root were annotated.

Statistical analysis. - Capsule length and diameter, as well as the effect of culture medium and light conditions on germination for each species were analyzed with a multivariate test of significance (for repeated measures). Days needed for full maturity were compared between genotypes with an analysis of variance. Subsequently, the Post hoc Tukey's HonestSignificant-Difference-Test (HSD) for unequal N (Spjotvoll/Stoline) was used to determine significant differences in the parameters tested $(\mathrm{p}<0.05)$. All analyses were conducted using Statistica 6.1 (StatSoft Inc., Tulsa, Oklahoma, U.S.A.).

\section{Results}

Pollination of flowers and capsule development. Blooming was observed in plants of $P$. longifolium and $P$. pearcei during the entire year, while $P$. humboldtii plants bloomed only in May and June. All manualpollinated flowers (three of $P$. humboldtii, nine of $P$. longifolium and 16 of $P$. pearcei) developed capsules.

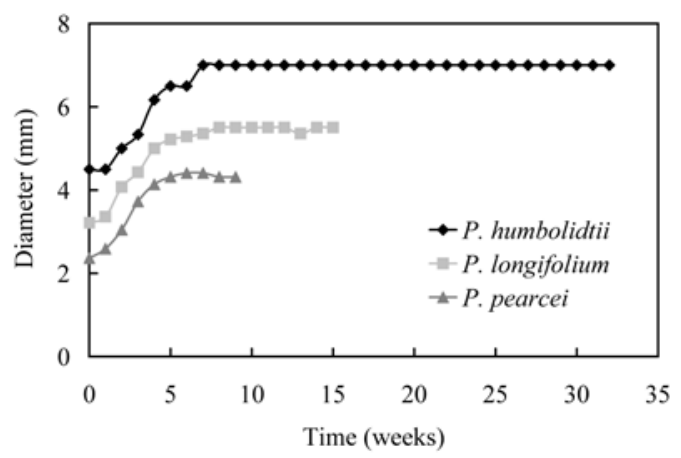

FIgURE 1. Diameter measured in capsules of $P$. humboldtii, $P$. longifolium and $P$. pearcei during development.

Capsule development, from pollination to opening, took longer in P. humboldtii ( $32 \pm 0.6$ weeks), than in P. longifolium and P. pearcei $(16 \pm 2.05$ and $9.8 \pm 0.6$ weeks, respectively).

Significant differences $(p<0.001)$ were measured in the capsule size of the three species (Fig 1). Largest capsules were those of $P$. humboldtii, with an average length of $182.7 \pm 3.2 \mathrm{~mm}$ and a diameter of $7.0 \pm 0.2 \mathrm{~mm}$ one week before opening. Capsules of $P$. longifolium were $60.02 \pm 2.0 \mathrm{~mm}$ in length and $5.6 \pm 0.1 \mathrm{~mm}$ in diameter, while those of $P$. pearcei were $42.5 \pm 1.4$ $\mathrm{mm}$ in length and $4.2 \pm 0.1 \mathrm{~mm}$ in diameter at the same moment (Fig. 1). During development, length of the capsules did not vary in any of the species studied ( $p>0.05$ ), while diameter increased during the first 6-8 weeks after pollination and then remained constant (Fig 1).

Capsules of $P$. humboldtii were light green and pubescent (Fig. 2A), while those of $P$. longifolium were dark purple without pubescence (Fig. 2B); capsules of $P$. pearcei were green-purple or totally purple, with short hairs (Fig. 2C). The capsules did not present notable changes in color or pubescence degree during maturation, except for those of $P$. humboldtii, which turned yellow 4-6 weeks before opening.

Seed viability. - A great difference in seed viability was observed between $P$. pearcei and the other species (Fig. 3). Average seed viability in the capsules of $P$. humboldtii was $34.3 \%$, in P. longifolium $44.7 \%$ and in $P$. pearcei $82.3 \%$. When the seed viability among different capsules of a single species was compared, values ranging from 20 to $80 \%$ were observed in $P$. pearcei and from 18 to $51 \%$ in P. humboldtii. 

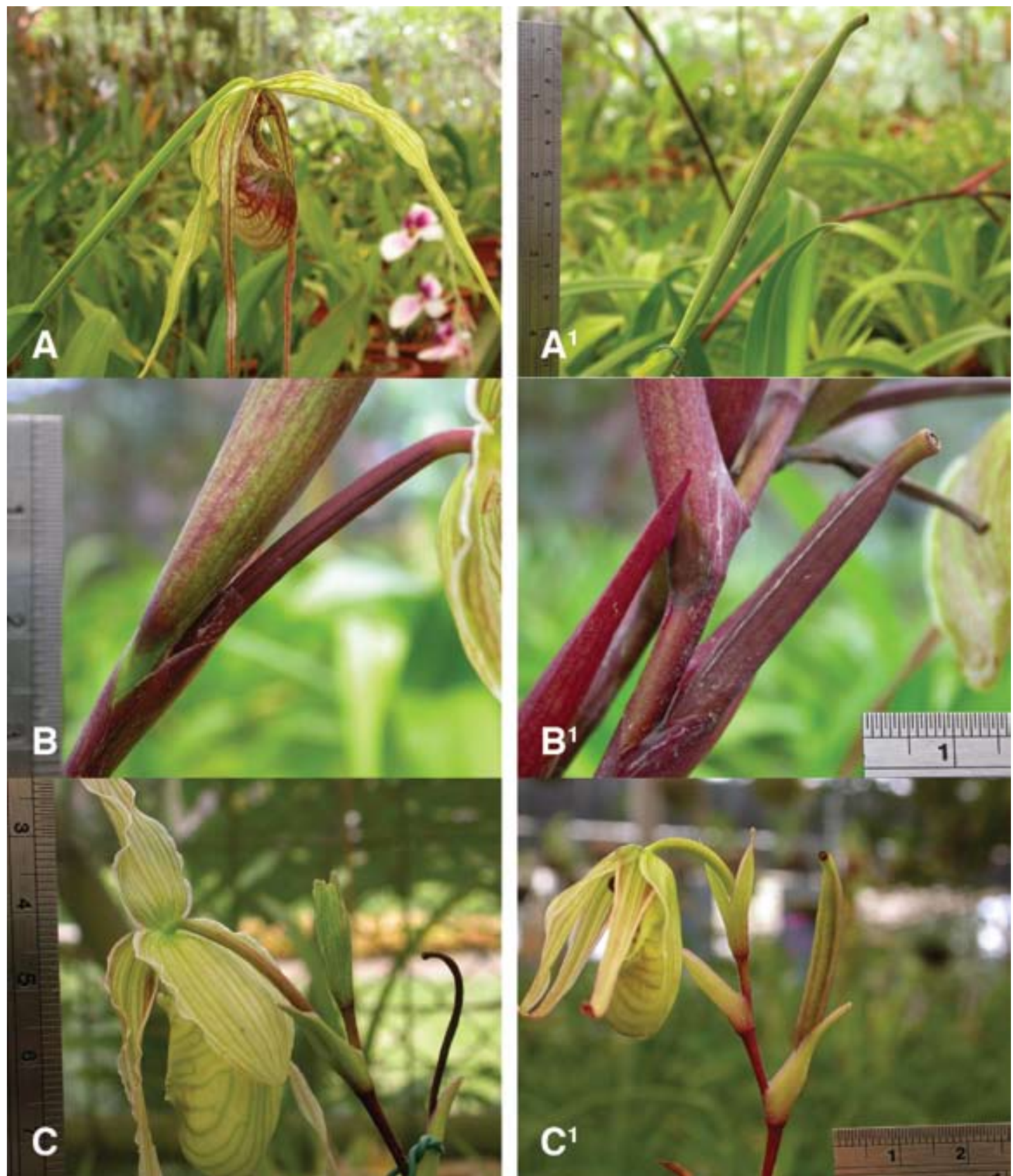

Figure 2. Development of capsules of P. humboldtii $\left(\mathrm{A}, \mathrm{A}^{1}\right)$, P. longifolium $\left(\mathrm{B}, \mathrm{B}^{1}\right)$ and P. pearcei $\left(\mathrm{C}, \mathrm{C}^{1}\right)$ at pollination day (left) and one week before capsule opening (right).

In vitro germination. - In order to consider only the viable seeds when calculating germination rate, percentage of seeds that germinated in the culture medium was corrected with the rate of viable seed measured for each capsule, as described in Materials and Methods. The corrected percentage of germination was lower in $P$. humboldtii $(2.9 \%)$ than in $P$. pearcei $(38.7 \%)$ and $P$. longifolium (41.3\%), without significant differences between the last two (Fig. 3). Developing protocorms that subsequently died were observed only in $P$. pearcei (Fig. 3). 


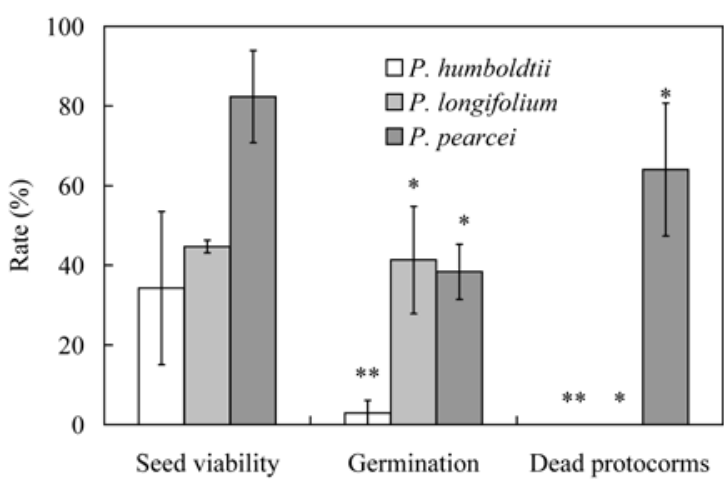

FIGURE 3. Seed viability, germination rate corrected with the percentage of seed viability of each capsule and death rate of germinated seeds in $P$. humboldtii, P. longifolium and $P$. pearcei. Data represent the mean of at least three replicates $\pm \mathrm{SD}$. *Four weeks after sowing. ${ }^{* *}$ Eight weeks after sowing.

Viable seeds of $P$. longifolium and P. pearcei started geminating during the first two weeks of culture. Afterwards, the germination rate decreased until, at week four, no additional germinating seeds were observed. On the other hand, germination in P. humboldtii occurred in a very low rate, with only a slight increase during the evaluated period of eight weeks (Fig. 4).

Culture medium had a significant effect on seed germination (Table 1), evident in P. longifolium and $P$. pearcei only during the first week by a higher germination rate on half-strength Murashige and Skoog medium. Thereafter, seed germination in these two species behaved very similarly (Fig. 4), without significant differences according to the Post-Hoc

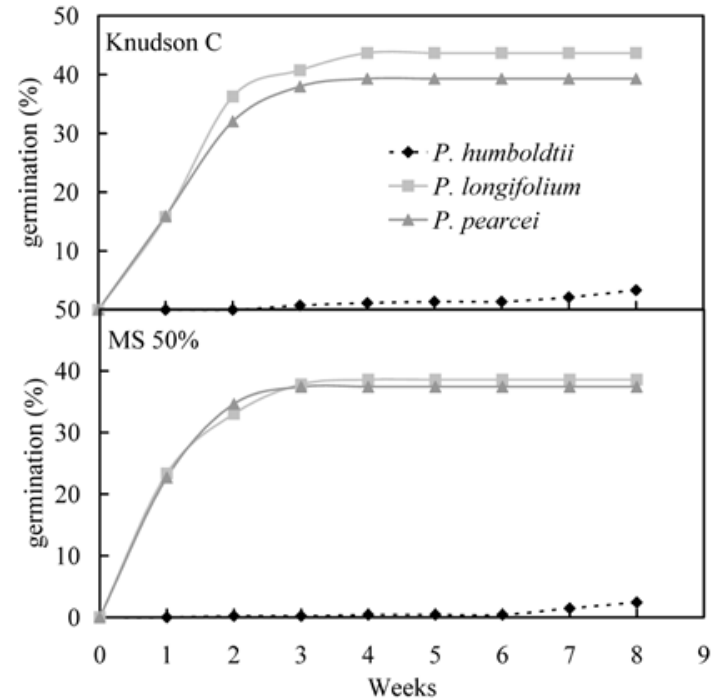

Figure 4. Germination rate in seeds of $P$. humboldtii, $P$. longifolium and P. pearcei along time on Knudson $\mathrm{C}$ and half-strength Murashige and Skoog media (MS 50\%).

Tukey's Honest-Significant-Difference-Test (HSD) for unequal N (Spjotvoll/Stoline).

No effect of the light conditions tested could be observed on seed germination in any of the evaluated species $(p>0.05)$ as presented in Table 1 . However, among the protocorms cultured on the Knudson $\mathrm{C}$ medium, a higher growth rate was observed afterwards in those germinated under dark conditions. The protocorms germinated in the dark were placed under a photoperiod of 12 hours of light after six weeks of culture, and one week later they began to change their color from white to green. By that time,

Table 1. Multivariate test of significance of seed germination corrected with the viability rate for each capsule of the three Phragmipedium species studied in response to culture medium and light conditions.

\begin{tabular}{|c|c|c|c|c|c|c|}
\hline Source of variation & Test & Value & $\mathbf{F}$ & Effect df & Error df & $\mathbf{p}$ \\
\hline Intercept & Wilks & 0.031021 & 226.4653 & 4 & 29 & 0.000000 \\
\hline Species (A) & Wilks & 0.038002 & 29.9406 & 8 & 58 & 0.000000 \\
\hline Culture medium (B) & Wilks & 0.451880 & 8.7941 & 4 & 29 & 0.000089 \\
\hline Light conditions (C) & Wilks & 0.757612 & 2.3195 & 4 & 29 & 0.080649 \\
\hline$A \times B$ & Wilks & 0.469325 & 3.3328 & 8 & 58 & 0.003338 \\
\hline$A \times C$ & Wilks & 0.421866 & 3.9122 & 8 & 58 & 0.000948 \\
\hline $\mathrm{B} \times \mathrm{C}$ & Wilks & 0.691800 & 3.2299 & 4 & 29 & 0.026159 \\
\hline $\mathrm{A} \times \mathrm{B} \times \mathrm{C}$ & Wilks & 0.454910 & 3.4992 & 8 & 58 & 0.002320 \\
\hline
\end{tabular}



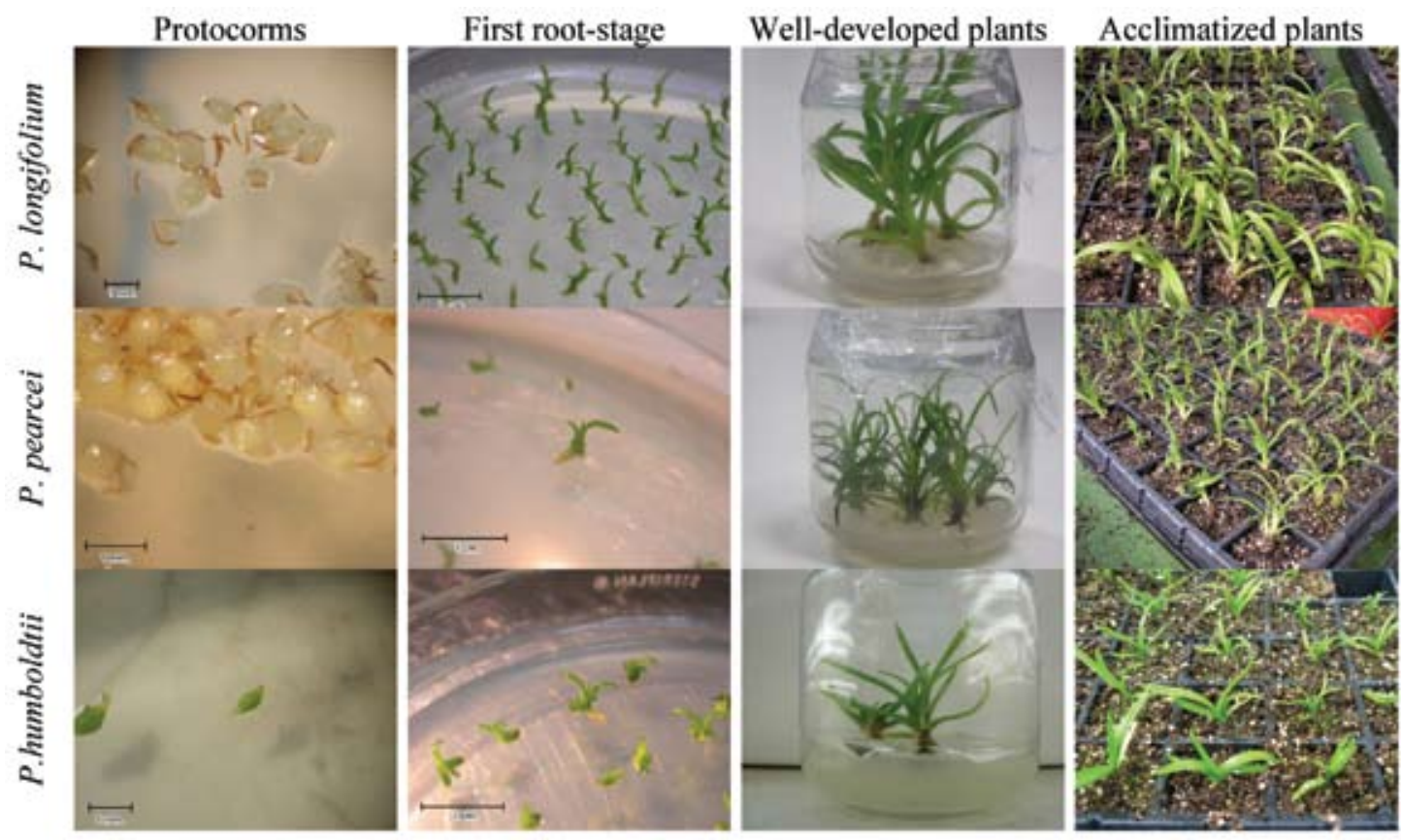

FIgURE 5. Stages during in vitro development of $P$. pearcei, P. longifolium and $P$. humboldtii cultured on MS 50\%.

the protocorms of $P$. pearcei and $P$. longifolium began to develop the first leaf. On the other hand, the first leaf of $P$. humboldtii appeared in the eighth week of culture. The seedlings of $P$. pearce $i$ and $P$. longifolium developed two or more leaves within the first three months, and began to develop roots in 3.5 months (Fig. 5). The plantlets of $P$. humboldtii developed their leaves in three months too, but began to develop roots only after five months in culture (Fig 5). Higher growth rate and better leaf development was observed with Knudson C (data not shown).

All plants were successfully acclimatized after ca. 15 months of culture in vitro (Fig. 5). After six months in the greenhouse, each plant of $P$. pearcei had $7.3 \pm 2.5$ roots, with the longest one measuring $10.4 \pm 1.7 \mathrm{~cm}$ in length. At the same moment, the plants of $P$. longifolium had $3.6 \pm 0.9$ roots, the longest one with $11.7 \pm 3.5 \mathrm{~cm}$.

\section{Discussion}

The time it takes an orchid capsule to reach fullmaturity varies according to genus and species. Times registered in this work for $P$. pearcei, $P$. longifolium and $P$. humboldtii (10, 16 and 32 weeks, respectively) were considerably shorter than those measured in other species belonging to the Cypripedioideae subfamily. For example, Paphiopedilum callosum capsules required between 47 and 48 weeks to open (Arditti 1992). Moreover, it is not unusual to observe differences in this respect between species belonging to the same genus. For example, while capsules of Laelia gouldiana needed 17 weeks to open, those of L. purpurata required 31 weeks. Similarly, in Dendrobium kingianum the time until full ripeness was 20 weeks, while in D. nobile it was 41 weeks (Arditti 1992).

Capsule development in the three Phragmipedium species studied characterized by an initial growing period of around eight weeks, followed by a maturation period in which the fruit did not increase in size until opening (Fig. 1). This growing pattern is commonly observed in many fruits. It is characterized by a sigmoid arrangement, in which cell division and elongation initially occur, followed by growth halt and finally the fruit reaches maturity (Agustí 2000). Those phases could vary in duration, depending on the species or genotype, as it was observed in the three Phragmipedium species studied here. 
Knowing the time the capsule of a particular orchid species requires until full maturity is very useful to determine proper harvesting time for in vitro germination. Ripe capsules usually have larger amounts of viable seeds than unripe ones. Moreover, collecting seeds after capsule opening usually reduces success during in vitro establishment due to contamination problems and damage caused by the sterilization process, and should be avoided when possible.

Seed viability measured in Phragmipedium (Fig. 3) is similar to that observed in other terrestrial orchids. For example, the seed viability of Cypripedium acaule varied from $20 \%$ to $40 \%$ in the capsules studied by Lauzer et al. (1994), and the viability of Calopogon tuberosus was $35 \%$ in the study conducted by Kauth et al. (2006). High values, as measured in P. pearcei in this study, have been observed in mature capsules of Ophrys (Kitsaki et al. 2004). Given that seed viability can vary significantly among capsules within the same species (up to $60 \%$, as observed in $P$. pearcei), it is important to evaluate viability in each capsule. This is necessary to assess the real effect of particular conditions on seed germination based on the actual amount of viable seeds per capsule.

The seeds of $P$. pearcei and $P$. longifolium germinated faster (2-3 weeks) (Fig. 4) than those of several terrestrial orchids. Henrich et al. (1981) showed that 7-12 weeks were necessary for the beginning of germination in 17 terrestrial orchid species. In the study of Shiau et al. (2002), the seeds of Anoectochilus formosanus germinated eight weeks after sowing. On the other hand, there are other terrestrial orchids that germinate faster, as in the case of $C$. tuberosus, whose seeds germinated one week after sowing and reached the maximum germination in 4-6 weeks (Kauth et al. 2006).

The percentage of germination in terrestrial orchids varies among species. Henrich et al. (1981) found $100 \%$ germination in Orchis fucssi and Epipactis gigantea, $75 \%$ in Goodyera oblongifolia and Spiranthes romanzoffiana, $50 \%$ in Platanthera stricta and Orchis macula, and 25\% in other seven species, Platanthera dilatata, Liparis laeselii and Cypripedium reginae among them. These authors also measured very low germination rates $(1 \%)$ in
Cypripedium calceolus, C. candidum, Plantanthera hiperboria and P. flava. However, they did not evaluate the viability of the seeds used; therefore the real percentage of germination of viable seeds could not be determined.

The seeds of $P$. humboldtii had very low germination rate $(2.9 \%)$ in spite of their relatively high viability (34.3\%). However, the large quantity of seeds in each capsule (data not shown) and the low rate of dead protocorms (Fig. 3) allowed the regeneration of enough plants using the protocol developed in this work for conservation and reintroduction of this species.

It has been considered that both germination and embryo staining (e.g., with tetrazolium chloride) are comparable viability tests. However, although the latter test has been successfully employed with epiphytic tropical orchids and several European and North American terrestrial orchids, there are some reports on inconsistencies in several species, probably attributed to variation in the permeability of the seed coat (reviewed by Vujanovic et al. 2000). In one of these cases, Lauzer et al. (1994) did not find any correlation between the percentage of germination and the percentage of seeds stained with tetrazolium chloride in Cypripedium acaule. They attributed these differences to a prolonged pretreatment with $\mathrm{NaOCl}$ (40 min with $0.6 \% \mathrm{w} / \mathrm{v}$ $\mathrm{NaOCl}$, as compared to $10 \mathrm{~min}$ with the same concentration in our study), a compound that can promote dormancy release in terrestrial orchid seeds (St-Arnaud et al. 1992).

Numerous orchid species grow better in the dark, mainly during the first phases of development. Activated carbon has also been used to darken the culture medium and, in this way, improve germination (Arditti and Ernst 1993). In some species, the role of light during germination is not clear; for example, some authors recommend germination of $C$. tuberosus in the dark and others in light conditions (reviewed by Kauth et al. 2006). The light or dark treatments did not have any effect over germination in the Phragmipedium species studied. However, larger protocorms in the three species were obtained in dark conditions. The protocorms that germinated in the dark were white because they do not produce 
chlorophyll; when they were placed in the light, the chlorophyll synthesis began, and their color changed to green, as observed in other orchids (Arditti \& Ernst 1993).

A considerable number of culture media has been successfully employed and even devised specifically for orchid seed germination, some of them being only slight modifications of others (Arditti 1967). Knudson C (Knudson 1946) and Murashige and Skoog (1962) mineral salts are probably the most commonly used formulations for asymbiotic germination of orchid seeds. Since the latter one contains high amounts of nitrogen, especially in form of ammonium, dilutions are frequently employed, such as in this investigation. For many orchids, the effect of media on germination and development appears to be genotype dependent. When Knudson $\mathrm{C}$ and half-strength Murashige and Skoog media were compared, some genotypes developed better in the former and others in the latter (Johnson and Kane 2007). There are also examples of equal response in both media (Roy and Banerjee 2002). This behavior could be related to the differences in the ammonioum:nitrate ratio of both media. Contrary to the results obtained with Phragmipedium in this work, half-strength Murashige and Skoog promoted better development of the developing seedlings of hybrid Vanda, as compared to Knudson C (Johnson and Kane 2007).

Although, to the best of our knowledge, acclimatization of in vitro-generated Phragmipedium orchids has not been reported in the scientific literature, this task should not be very difficult, since it seems to be routinely conducted by commercial growers. Very high survival rates during acclimatization, as reported in the present work, indicate that plants generated in vitro were in adequate conditions and could adapt with few problems to the reduced relative humidity in the greenhouse and become autotrophic. This seems to be the case in the present work, since $100 \%$ success was obtained in this step.

In this work an efficient protocol for seed germination and plantlet growth of three Phragmipedium species was described. The combination of Knudson $\mathrm{C}$ medium and culture in the dark during the first six weeks seems to be appropriate to reach a good germination percentage and initial protocorm development. Following the method described in this work it was possible to grow plants of the three Phragmipedium species studied and to achieve their acclimatization in the greenhouse. A great quantity of plants could be produced by in vitro germination, maintaining larger genetic variability than with clonal propagation. This is a useful tool for the conservation of these species.

ACKNOWLEDGMENTS. This investigation was partially funded by the Universidad de Costa Rica (project number VI-814-A6-107). Authors wish to thank J. Warner for facilitating the plants used in this study and for additional support. Helpful comments from anonymous reviewers are gratefully acknowledged.

\section{Literature Cited}

Agustí, M. 2000. Crecimiento y maduración del fruto. In: Azcón-Bieto, J. \& M. Talón (eds.). Fundamentos de Fisiología Vegetal. Mc Graw-Hill, Madrid, Spain, 419433.

Arditti, J. 1967. Factors affecting the germination of orchid seeds. Bot. Rev. 33: 1-97.

Arditti, J. 1992. Fundamentals of orchid biology. John Wiley \& Sons, U.S.A. 691 p.

Arditti, J. \& R. Ernst. 1993. Micropropagation of orchids. John Wiley \& Sons, New York, U.S.A. 682 p.

Arditti, J. \& A.K.A. Ghani. 2000. Numerical and physical properties of orchid seeds and their biological implications. New Phytol. 145: 367-421.

Cox, A.V., A.M. Pridgeon, V.A. Albert \& M.W. Chase. 1997. Phylogenetics of the slipper orchids (Cypripedioideae, Orchidaceae): nuclear rDNA ITS sequences. Plant Syst. Evol. 208: 197-223.

Cox, A.V., A.M. Pridgeon \& M.W. Chase. 1998. The utility of DNA sequence data in orchid systematics: an example from the slipper orchids (Cypripedioideae). In: C.E.B. Pereira (ed.). Proceedings of $15^{\text {th }}$ World Orchid Conference. Naturalia, France, 265-273.

Decruse, S.W., A. Gangaprasad, S. Seeni \& V.S. Menon. 2003. Micropropagation and ecorestoration of Vanda spathulata, an exquisite orchid. Plant Cell Tiss. Organ Cult. 72: 199-202.

Dressler, R.L. 2003. Orchidaceae. In: Hammel, B.E., Grayum, M.H., Herrera, C. \& Zamora, N. (eds.). Manual de plantas de Costa Rica, vol III: Monocotiledóneas (Orchidaceae-Zingiberaceae). Missouri Botanical Garden. Saint Louis, Missouri, U.S.A., 1-595. 
Gangaprasad, A.N., W.S. Decruse, S. Seeni \& S. Menon. 1999. Micropropagation and restoration of the endangered Malabar daffodil orchid Ipsea malabarica. Lindleyana 14: 38-46.

Guerrant, E.O. \& T.N. Kaye. 2007. Reintroduction of rare and endangered plants: common factors, questions and approaches. Austr. J. Bot. 55: 362-370.

Henrich, J.F., D.P. Stimart \& P.D. Ascher. 1981. Terrestrial orchid seed germination in vitro on a defined medium. J. Amer. Soc. Hort. Sci. 106: 193-196.

Johnson, T.R. \& M.E. Kane. 2007. Asymbiotic germination of ornamental Vanda: in vitro germination and development of three hybrids. Plant Cell Tiss. Organ Cult. 91: 251-261.

Kauth, P.J., W.A. Vendrame \& M. Kane. 2006. In vitro seed culture and seedling development of Calopogon tuberosus. Plant Cell Tiss. Organ Cult. 85: 91-101.

Kitsaki, C.K., S. Zygouraki, M. Ziobora \& S. Kintzios. 2004. In vitro germination, protocorm formation and plantlet development of mature versus immature seeds from several Ophrys species (Orchidaceae). Plant Cell Rep. 23: 284-290.

Knudson, L. 1946. A new nutrient solution for the germination of orchid seed. Amer. Orchid Soc. Bull. 15: 214-217.

Lauzer, D., M. St-Arnaud \& D. Barabé. 1994. Tetrazolium staining and in vitro germination of mature seeds of Cypripedium acaule (Orchidaceae). Lindleyana 9: 197204.

Murashige, T. \& F. Skoog. 1962. A revised medium for rapid growth and bioassays with tobacco tissue culture. Physiol. Plant. 15: 473-497.

Ramsay, M.M. \& K.W. Dixon. 2003. Propagation science, recovery and translocation of terrestrial orchids. In: Dixon, K.W., S.P. Kell, R.L. Barrett \& P.C. Cribb (eds.). Orchid conservation. Natural History Publications, Malaysia, 259-288.

Roy J., \& N. Banerjee. 2002. Optimization of in vitro seed germination, protocorm growth and seedling proliferation of Vanda tessellate (Roxb.) Hook Ex G Don. Phytomorphology 52: 167-178.

Rubluo, A., V. Chávez \& A. Martínez. 1989. In vitro seed germination and re-introduction of Bletia urbana (Orchidaceae) in its natural habitat. Lindleyana 4: 6873.

Salazar, G.A. 1996. Conservation threats. In: Hágsater, E \& V. Dumont (eds.). Orchids - Status survey and conservation action plan. IUCN. Gland, Switzerland and Cambridge, U.K., 6-10.

Salazar, V.M. \& M. Mata. 2003. Micropropagación y conservación de orquídeas mexicanas en el Jardín Botánico Clavijero. Lankesteriana 7: 151-153.

Sarasan, V., R. Cripps, M.M. Ramsay, C. Atherton, M. McMichen, G. Prendergast \& J.K. Rowntree. 2006. Conservation in vitro of threatened plants - progress in the past decade. In Vitro Cell. Devel. Biol. - Plant 42: 206-214.

Shiau, Y.J., A.P. Sagare, U.C. Chen, S.R. Yang \& H.S. Tsay. 2002. Conservation of Anoectochilus formosanus Hayata by artificial cross-pollination and in vitro culture of seeds. Bot. Bull. Acad. Sin. 43: 123-130.

Singh, F. 1981. Differential staining of orchid seeds for viability testing. Amer. Orchid Soc. Bull. 50: 416-418.

St-Arnaud, M., D. Lauzer \& D. Barabé. 1992. In vitro germination and early growth of seedlings of Cypripedium acaule (Orchidaceae). Lindleyana 7: 2227.

Stenberg, M.L. \& M.E. Kane. 1998. In vitro seed germination and greenhouse cultivation of Encyclia boothiana var. erythronioides, an endangered Florida orchid. Lindleyana 13: 101-112.

Steward, S.L., L.W. Zettler \& J. Minso. 2003. Symbiotic germination and reintroduction of Spiranthes brevilabris Lindley, an endangered orchid native to Florida. Selbyana 24: 64-70.

Vujanovic, V., M. St-Arnaud, D. Barabé \& G. Thibeault. 2000. Viability testing of orchid seed and the promotion of colouration and germination. Ann. Bot. 86: 79-86. 
LANKESTERIANA 